\title{
LOS CAMBIOS EN EL SISTEMA INTERNACIONAL A PARTIR DE 2000
}

JoRge I. Domínguez ${ }^{1}$

¿Cómo ES QUE LA ESTRUCTURA del sistema internacional abre oportunidades y establece limitaciones que inciden en las políticas exteriores de los Estados? ¿Cuáles son los elementes fundamentales del sistema internacional? ¿Qué consecuencias tiene en el comportamiento internacional de los Estados que estos elementos sufran cambios fundamentales? ¿Cómo ha cambiado el sistema internacional en este siglo y de qué manera estos cambios imitan o se distinguen de otras alteraciones similares importantes en la estructura del sistema internacional del pasado?

Para concentrarse con mayor precisión en las características significativas de los cambios sistémicos más recientes, este artículo empieza por describir los componentes principales de tres momentos de cambio en la estructura del sistema internacional a lo largo de los últimos doscientos años. Después, se examinan cinco características fundamentales de los cambios en el sistema internacional en el siglo xx: $a$ ) las oportunidades que el ascenso de China en los mercados globales creó para los Estados de América Latina; b) las capacidades mejoradas de los Estados latinoamericanos en relación con los grandes poderes y las instituciones financieras internacionales como resultado del auge internacional de los mercados de materias primas durante la primera década del siglo; $c$ ) el

\footnotetext{
${ }^{1}$ Agradezco a la Fundación Vidanta su apoyo en la realización de este trabajo y al Centro Weatherhead de Asuntos Internacionales de la Universidad de Harvard el apoyo general a mi obra. También quiero agradecer la ayuda de Aaron Watanabe en la investigación para las tablas estadísticas.
} 
trastorno del sistema internacional a causa de la política exterior estadounidense de principios del siglo xxi y el consiguiente esfuerzo por encontrar un equilibrio frente al poder estadounidense; $d$ ) el desmoronamiento del consenso ideológico interamericano que había surgido en la década de 1990 y que dio lugar a una heterogeneidad normativa más amplia en el comportamiento estatal; y e) el intensificado matiz de seguridad de las relaciones bilaterales con Estados Unidos, particularmente en el caso de los Estados latinoamericanos que están más al norte.

\section{EL DESMORONAMIENTO DE TRES SISTEMAS INTERNACIONALES}

"El Zar de Rusia nunca recuperó [...] la posición dominante que ostentaba cuando abdicó Napoleón [...] Pensaba que, entre los monarcas, era el único intérprete y defensor de los principios del liberalismo cristiano [...] [e] imaginaba que los puntales del interés nacional podrían de alguna manera desvanecerse [...] con el ungüento de su volátil benevolencia”. ${ }^{2}$ Así lo describió, en 1946, el diplomático e historiador Sir Harold Nicolson cuando intentaba aprender del pasado a través de las circunstancias que, en la historia de la reestructuración del sistema internacional, más se asemejaban a las de su tiempo, es decir, las de Europa en 1814. Con la capitulación de Napoleón,

- un Estado sostén del sistema internacional fue derrotado de manera contundente;

- un imperio poderoso se fragmentó;

- la estructura del sistema internacional se volvió decididamente asimétrica, en beneficio de la coalición vencedora;

- la historia internacional, que había sido la historia del interés nacional, llegó a su fin: la nueva coalición hegemónica declaró la validez universal de su ideología como base de su propia legitimidad, como estándar para alcanzar el acatamiento de los demás y como justificación para intervenir en los asuntos internos de otros

${ }^{2}$ Harold Nicolson, The Congress of Vienna: A Study in Allied Unity, 1812-1822, Nueva York, The Viking Press, 1961, p. 102. 
países (este ejercicio de poder se presentaba como bueno y benigno, incluso para las naciones blanco de una intervención);

- la conducta del poder líder vencedor debilitaba su propio triunfo poco después de la victoria y la volatilidad de dicho comportamiento contribuía a que perdiera su primacía.

Las primeras tres observaciones de esta lista también se presentaron al final de la Primera Guerra Mundial. Sin embargo, tras la revolución bolchevique, no hubo un consenso ideológico de posguerra que ofreciera un nuevo principio de orden para el sistema internacional o que justificara una intervención consensuada en los asuntos internos de otros países. En cambio, el comportamiento de varios de los Estados victoriosos sí contribuyó a que perdieran su influencia rápidamente. El mundo que dejó la Segunda Guerra Mundial también difiere de la Europa postnapoleónica en tanto que no hubo un consenso ideológico para reordenar el sistema internacional; por el contrario, había dos ideologías opuestas y ambas se utilizaban para justificar intervenciones trasfronterizas. La obra de Nicolson es anterior a la cristalización de la Guerra Fría, conque no contemplaba la división de la coalición triunfadora que surgió después de la Segunda Guerra Mundial, aunque ésta no tardó demasiado en producirse. El 1946 que describe Nicolson se asemejaba a 1814, y 1991 se parecía a los dos.

Aunque su caída no hubiera sido precedida por ninguna guerra mundial, para 1991 la Unión Soviética había sido totalmente derrotada. La URSS se fragmentó en las repúblicas que hasta entonces la conformaban y la estructura del sistema internacional se volvió terriblemente asimétrica para beneficio de la coalición encabezada por Estados Unidos. Sin embargo, una diferencia respecto a lo que se vio en 1814 y en 1945 es que en 1991 Estados Unidos mantenía una supremacía indiscutible dentro y más allá de su propia coalición. En este sentido, se puede decir que la notoriedad estadounidense a principios de la década de 1990 no tenía precedente en la historia del sistema internacional moderno.

Igual que en 1814, los vencedores sostenían la validez universal de su ideología hegemónica como base de su propia legitimidad, como estándar para alcanzar el acatamiento de los demás y como justificación para intervenir en los asuntos internos de otros 
países. En The End of History and the Last Man, ${ }^{3}$ Francis Fukuyama argumentó que había triunfado la democracia liberal y que ya no había una base alterna útil, loable o universalmente aceptada para sustentar la legitimidad política interna. Conceptos como la "promoción de la democracia", la "intervención humanitaria" o la "responsabilidad de proteger" a las víctimas de la violencia o el abuso intentaban justificar el despliegue de la fuerza en asuntos internos de otros países a favor de un bien común superior y de aplicación universal.

Los cambios en el sistema internacional dieron lugar también a un segundo giro ideológico. La caída de los regímenes comunistas en el Este de Europa central fue fundamental, no sólo para reestructurar el sistema internacional en términos de poder, sino también porque, en el escenario mundial, impulsó el triunfo de las ideologías democrático liberales y orientadas al mercado con una fuerza y persuasión que hasta entonces no habían conseguido. Estos países europeos se habían liberado del control soviético y, al mismo tiempo, habían adoptado nuevas maneras de pensar, justificar y arreglar sus asuntos económicos y políticos internos. Los poderes hegemónicos triunfantes no eran los únicos que alimentaban las nuevas ideologías democrático liberales y orientadas al mercado; la mayoría de los Estados otrora subordinados a la Unión Soviética también demandaban la aplicación y defensa de esas ideologías. Para fines prácticos, todos los antiguos aliados del Pacto de Varsovia soviético -salvo la propia Unión Soviética-y los tres Estados bálticos que habían formado parte de la URSS entraron a formar parte de la Unión Europea.

La historia del cuarto de siglo que siguió al colapso de la Unión Soviética es la historia del desencadenamiento de esta estructura internacional en la que Estados Unidos afirma encabezar una hegemonía ideológica de consenso. En este capítulo se muestra, en primer lugar, cómo estos cambios en el sistema internacional dieron una nueva configuración a las relaciones internacionales en el continente americano en la década de 1990. Después, se analiza el nuevo equilibrio del sistema internacional del que hemos sido testigos en el

\footnotetext{
${ }^{3}$ Nueva York, Free Press, 1991.
} 
siglo XXI y su consiguiente efecto en las relaciones internacionales en América. Particular atención se presta al crecimiento de China. Una de las consecuencias de este fenómeno fue permitir que los Estados latinoamericanos más grandes desarrollaran nuevas capacidades para su actividad nacional e internacional. Más adelante se evalúa cómo el gobierno estadounidense ha afectado su propia primacía internacional. Finalmente, se abordan dos temas que abarcan un campo más limitado; a saber, el desmoronamiento del consenso ideológico en torno al constitucionalismo democrático liberal y a las políticas económicas a favor del mercado en el continente americano, y los aspectos de seguridad de las relaciones entre Estados Unidos y América Latina.

EL REORDENAMIENTO DEL SISTEMA INTERNACIONAL EN EL CONTINENTE AMERICANO EN LA DÉCADA DE 1990

La caída de la Unión Soviética y el fin de la Guerra Fría en Europa tuvieron consecuencias inmediatas en el continente americano. Se acabaron las guerras internas y entre Estados que habían conmocionado a América Central a lo largo de casi una generación. Entre los muchos factores que convergieron para este resultado, se encuentra la suspensión del apoyo militar, político y económico de la URSS a Cuba, cuya economía se colapsó a principios de la década de 1990. La consiguiente imposibilidad de que la isla caribeña o cualquier otro aliado soviético apoyaran a sus allegados en la región generó mayores incentivos para el establecimiento de la paz en Nicaragua, El Salvador y Guatemala. Además, en un plano más amplio, Cuba retiró a sus tropas de Angola, Etiopía y de alrededor de una docena de países más y perdió la importancia militar que había adquirido en los últimos años de la Guerra Fría. En varias naciones latinoamericanas hubo partidos comunistas que se disolvieron o que se fusionaron para convertirse en partidos nuevos formados a partir de coaliciones de izquierda que centraron su atención en temas de carácter interno.

Sin embargo, en el Hemisferio Occidental, la principal amenaza de intervención en el ámbito nacional durante la Guerra Fría 
provino de Estados Unidos y no de la Unión Soviética. ${ }^{4}$ Durante este periodo, las tropas estadounidenses invadieron la República Dominicana, Granada y Panamá, y fuerzas auspiciadas por ese mismo país invadieron Guatemala, Cuba y Nicaragua. ${ }^{5}$ Estados Unidos apoyó de manera exitosa a actores internos que derrocaron a varios gobiernos. Por su parte, aunque Cuba respaldó en repetidas ocasiones a insurgentes que buscaban la destitución de sus gobiernos, sólo estuvo del lado vencedor en el caso de Nicaragua.

A partir de 1991, liberados de los demonios de la Guerra Fría -el temor ante la actividad soviética y cubana y la presencia comunista por doquier-, Estados Unidos abandonó una actitud tan marcadamente intervencionista en el continente, salvo en Haití. Por lo tanto, la reestructuración del sistema internacional modificó también el sistema de relaciones internacionales en el Hemisferio Occidental. El triunfo estadounidense a nivel mundial permitió a Estados Unidos contener sus acciones unilaterales en el resto de América.

La transición latinoamericana hacia regímenes políticos democráticos empezó en la República Dominicana en 1978 con la intervención "suave" del gobierno estadounidense para obligar al presidente en funciones, Joaquín Balaguer, a abstenerse de recurrir al fraude electoral y aceptar la victoria de la oposición. Sin embargo, las transiciones democráticas que siguieron a lo largo y ancho de América del Sur en la década de 1980 se lograron sin la intervención del gobierno de Reagan quien, en su primer periodo, parecía simpatizar bastante con los regímenes autoritarios. ${ }^{6}$ Una vez más, Estados Unidos empezó a desempeñar un papel a favor de la democracia en Chile y Paraguay y promovieron fórmulas democrático liberales como parte de los acuerdos en Centroamérica. Sin embargo, también firmaron el Tratado de Libre Comercio de América del Norte

${ }^{4}$ Cole Blasier, The Giant's Rival: The USSR and Latin America, edición revisada, University of Pittsburgh Press, 1985.

${ }^{5}$ Cole Blasier, The Hovering Giant: U.S. Responses to Revolutionary Change in Latin America, edición revisada, Pittsburgh, University of Pittsburgh Press, 1985.

${ }^{6}$ La evaluación clásica de transiciones democráticas en el Sur de Europa y en América del Sur no menciona en absoluto a Estados Unidos. Véase Guillermo O'Donnell y Philippe Schmitter, Transitions from Authoritarian Rule, Baltimore, The Johns Hopkins University Press, 1986. 
(TLCAN) sin incluir una "cláusula de democracia”, lo que significa que, al inicio del tratado, los miembros no estaban obligados a tener un régimen democrático liberal consolidado, que México no tenía. En términos generales, la intervención del gobierno estadounidense en América Latina sólo contribuyó al triunfo de la política democrático liberal en los países más pequeños y en Chile, donde fue un factor secundario y tardío aunque, a fin de cuentas, con resultados positivos. ${ }^{7}$ Independientemente de los distintos caminos y orígenes, podemos afirmar que, a principios de la década de 1990, el consenso democrático liberal en América Latina era generalizado, estaba arraigado y era positivamente notorio en todo el continente, salvo en Cuba y México, aunque este último ya transitara por el cambio político.

Aunada a una serie de factores importantes de carácter nacional en muchos países, la reestructuración del sistema internacional contribuyó a la construcción de una hegemonía democrático liberal a principios de la década de 1990. La aplicación de esta ideología hegemónica en la regulación de las relaciones internacionales en el continente americano fue el resultado del acuerdo explícito entre gobiernos. Estados Unidos ya no intervendría unilateralmente (la excepción fue Haití en 1994 y 2004), sino que habría una intervención colectiva. En Santiago de Chile (1991), los miembros de la Organización de Estados Americanos (OEA) suscribieron la Resolución 1080 que obligaba a los Estados miembros a contrarrestar cualquier intento por derrocar a un gobierno democrático en América. En diciembre de 1992, los Estados miembros de la OEA enmendaron, a través del Protocolo de Washington, la Carta de la oEA a fin de autorizar, con el voto de dos terceras partes de los miembros en la Asamblea General, la suspensión en la oEA de cualquier gobierno que hubiera obtenido el poder a través de la fuerza. Hace dos siglos, tras el Congreso de Viena, los Estados hegemónicos victoriosos hubieran definido este resultado como una "Santa Alianza" para proteger y promover las instituciones y prácticas democráticas. En 1992, con el argumento de que era incorrecto autorizar facultades e instrumentos

7 Thomas Carothers, In the Name of Democracy: U.S. Policy toward Latin America in the Reagan Years, Berkeley, University of California Press, 1991. 
supranacionales para intervenir en los asuntos internos de los miembros, México fue el único país que votó en contra de la reforma a la Carta de la OeA. ${ }^{8}$

Por lo tanto, los Estados miembros rasgaron el velo de no intervención que sus predecesores habían querido construir a lo largo del siglo anterior. En la década de 1990, la acción colectiva para detener o revertir golpes de Estado condujo a importantes intervenciones en los asuntos nacionales de varios países latinoamericanos. Destacan en particular el desembarco de tropas estadounidenses en Haití en 1994 (que más adelante fueron remplazadas por una fuerza multilateral); la exitosa oposición a los golpes de Estado en Guatemala y Paraguay (esta última, gracias a acciones del Mercado Común del Sur -Mercosur- y Estados Unidos), y la mitigación y monitoreo intermitente de la política nacional peruana.

En congruencia con este sistema internacional reestructurado e ideológicamente liberal, la acción colectiva en América adoptó nuevas formas. Muchos Estados latinoamericanos han contribuido de manera más activa con personal de mantenimiento de la paz en misiones de las Naciones Unidas. Cabe destacar el establecimiento de una presencia ininterrumpida de la onU en Haití a partir de abril de 2004 con 6700 elementos militares y 1622 oficiales de policía y en la que, diez años más tarde, todavía participaban 5165 elementos militares y 2466 oficiales de policía. Durante este periodo, las fuerzas de la Organización, proporcionadas por nueve Estados sudamericanos y tres centroamericanos, han estado bajo el mando de Brasil. ${ }^{9}$

También hemos sido testigos de un renovado esfuerzo por establecer acuerdos minilaterales de integración regional que, comparados con los de la década de 1960, ponen mayor énfasis en el contenido económico con una orientación al mercado. El Mercado Común del Sur (Mercosur ${ }^{10}$ ), el Mercado Común Centroamericano, la Comunidad Andina y el TLCAN son los ejemplos más importantes.

${ }^{8}$ Organización de Estados Americanos, Actas y documentos, Washington, OEA/ Ser.P/XVI-E, 14 de diciembre de1992, 53.

${ }^{9}$ http://www.un.org/en/peacekeeping/missions/minustah/facts.shtml De los países latinoamericanos más grandes, Cuba, México y Venezuela son los que no han contribuido con personal para el mantenimiento de la paz en Haití.

${ }^{10}$ Mercosul es el acrónimo en portugués. 
TABLA 1.1

Exportaciones a China de los países latinoamericanos seleccionados, millones de dólares estadounidenses por año

\begin{tabular}{|c|c|c|c|c|c|c|c|c|}
\hline & Argentina & Brasil & Chile & Colombia & Cuba* & México & Perú & Venezuela \\
\hline \multirow[t]{2}{*}{2000} & 797 & 1085 & 906 & 29 & 78 & 204 & 446 & 23 \\
\hline & $(3.0)$ & (1.8) & $(4.7)$ & $(0.2)$ & $(5.0)$ & $(0.1)$ & $(6.5)$ & $(0.1)$ \\
\hline \multirow[t]{2}{*}{2001} & 1124 & 1902 & 1015 & 20 & 104 & 282 & 426 & 42 \\
\hline & $(4.2)$ & $(3.2)$ & $(5.5)$ & $(0.2)$ & $(6.6)$ & $(0.2)$ & $(6.1)$ & $(0.2)$ \\
\hline \multirow[t]{2}{*}{2002} & 1092 & 2520 & 1233 & 27 & 105 & 654 & 599 & 91 \\
\hline & $(4.2)$ & $(4.2)$ & $(6.7)$ & $(0.2)$ & $(7.0)$ & $(0.4)$ & $(7.8)$ & $(0.3)$ \\
\hline \multirow[t]{2}{*}{2003} & 2483 & 4533 & 1909 & 81 & 110 & 974 & 680 & 165 \\
\hline & $(8.3)$ & $(6.2)$ & $(8.8)$ & $(0.6)$ & $(6.9)$ & $(0.6)$ & $(7.7)$ & $(0.6)$ \\
\hline \multirow[t]{2}{*}{2004} & 2628 & 5440 & 3442 & 135 & 177 & 986 & 1240 & 277 \\
\hline & $(7.6)$ & $(5.6)$ & $(10.4)$ & $(0.8)$ & $(8.4)$ & $(0.5)$ & $(9.9)$ & $(0.7)$ \\
\hline \multirow[t]{2}{*}{2005} & 3193 & 6834 & 4895 & 236 & 216 & 1136 & 1886 & 293 \\
\hline & $(7.9)$ & $(5.8)$ & $(11.7)$ & (1.1) & $(10.7)$ & $(0.5)$ & $(10.9)$ & $(0.5)$ \\
\hline \multirow[t]{2}{*}{2006} & 3476 & 8400 & 5255 & 439 & 480 & 1688 & 2277 & 206 \\
\hline & $(7.5)$ & (6.1) & $(8.8)$ & (1.8) & $(19.9)$ & $(0.7)$ & $(9.6)$ & $(0.3)$ \\
\hline \multirow[t]{2}{*}{2007} & 5170 & 10749 & 10505 & 769 & 1005 & 1895 & 3041 & 2006 \\
\hline & $(9.2)$ & $(6.8)$ & $(15.3)$ & (2.6) & $(29.4)$ & $(0.7)$ & $(11.0)$ & (2.9) \\
\hline \multirow[t]{2}{*}{2008} & 6355 & 16403 & 8519 & 443 & 821 & 2045 & 3736 & 3481 \\
\hline & $(9.1)$ & $(8.3)$ & $(13.2)$ & (1.2) & $(26.6)$ & $(0.7)$ & (12.0) & $(3.7)$ \\
\hline \multirow[t]{2}{*}{2009} & 3668 & 18798 & 13028 & 950 & 522 & 2208 & 4056 & 3320 \\
\hline & $(6.6)$ & $(12.5)$ & $(23.5)$ & (2.9) & $(23.5)$ & $(1.0)$ & $(15.3)$ & (5.8) \\
\hline \multirow[t]{2}{*}{2010} & 5796 & 30786 & 17324 & 1967 & 696 & 4183 & 5423 & 5071 \\
\hline & $(8.6)$ & $(15.2)$ & $(24.4)$ & $(5.0)$ & $(27.1)$ & $(1.4)$ & $(15.5)$ & (7.7) \\
\hline \multirow[t]{2}{*}{2011} & 6024 & 44315 & 18629 & 1979 & 822 & 5964 & 6961 & 11586 \\
\hline & $(7.3)$ & $(17.3)$ & $(22.9)$ & $(3.5)$ & $(23.8)$ & $(1.7)$ & $(15.2)$ & (12.7) \\
\hline \multirow[t]{2}{*}{2012} & 5001 & 41228 & 18098 & 3343 & 517 & 5721 & 7779 & 13119 \\
\hline & (6.4) & $(17.0)$ & $(23.2)$ & $(5.5)$ & $(16.6)$ & $(1.5)$ & (17.1) & $(14.5)$ \\
\hline \multirow[t]{2}{*}{2013} & 5542 & 46026 & 19090 & 5100 & 459 & 6467 & 7201 & 11929 \\
\hline & (7.1) & $(19.0)$ & $(24.9)$ & (8.7) & $(15.1)$ & $(1.7)$ & (17.8) & $(14.0)$ \\
\hline
\end{tabular}

Fuente: Directorio de estadísticas comerciales del Fondo Monetario Internacional. http:/ / elibrary-data.imf.org/finddatareports.aspx?d=33061\&e=170921 Último acceso: 4 de junio de 2014.

Los valores en paréntesis reflejan las exportaciones a China como porcentaje del total de exportaciones.

* Las exportaciones a China de Cuba de acuerdo a registros de socios; el total de las exportaciones totales de Cuba provienen de registro de socios y cálculos.

Los valores de 2013 para Argentina, Perú y Venezuela $(2012,2013)$ son preliinares, incluyendo cálculos. 
TABla 1.2

Importaciones de China a los países latinoamericanos seleccionados, millones de dólares por año

\begin{tabular}{|c|c|c|c|c|c|c|c|c|}
\hline & Argentina & Brasil & Chile & Colombia & Cuba & México & Perú & Venezuela \\
\hline \multirow[t]{2}{*}{2000} & 1157 & 1344 & 950 & 172 & 257 & 3168 & 329 & 187 \\
\hline & $(4.6)$ & $(2.2)$ & $(5.1)$ & (1.5) & (6.8) & (1.6) & $(4.1)$ & $(1.0)$ \\
\hline \multirow[t]{2}{*}{2001} & 1066 & 1461 & 1014 & 475 & 366 & 4430 & 409 & 348 \\
\hline & $(5.2)$ & (2.4) & $(5.7)$ & (3.7) & (10.3) & (2.4) & $(5.2)$ & (1.6) \\
\hline \multirow[t]{2}{*}{2002} & 330 & 1709 & 1102 & 516 & 341 & 6902 & 260 & 227 \\
\hline & (3.7) & (3.3) & $(6.5)$ & $(4.2)$ & (11.4) & $(3.7)$ & (3.2) & (1.5) \\
\hline \multirow[t]{2}{*}{2003} & 720 & 2362 & 1642 & 674 & 260 & 10341 & 315 & 157 \\
\hline & $(5.2)$ & (4.4) & $(8.5)$ & $(5.0)$ & $(8.8)$ & $(5.5)$ & $(3.5)$ & (1.9) \\
\hline \multirow[t]{2}{*}{2004} & 883 & 4081 & 2472 & 1052 & 364 & 15811 & 358 & 392 \\
\hline & (3.9) & (5.9) & $(10.0)$ & (6.4) & (7.6) & $(7.3)$ & (3.3) & (2.6) \\
\hline \multirow[t]{2}{*}{2005} & 1528 & 5889 & 3227 & 1612 & 699 & 19466 & 1139 & 808 \\
\hline & (5.3) & (7.3) & $(9.8)$ & $(7.6)$ & $(9.9)$ & $(8.0)$ & (8.6) & $(3.7)$ \\
\hline \multirow[t]{2}{*}{2006} & 3122 & 8788 & 4393 & 2158 & 1388 & 26882 & 1678 & 1485 \\
\hline & $(9.1)$ & (8.7) & (11.3) & $(8.5)$ & $(15.0)$ & $(9.5)$ & $(10.3)$ & $(4.9)$ \\
\hline \multirow[t]{2}{*}{2007} & 5093 & 13880 & 6064 & 3270 & 1286 & 32718 & 2571 & 2807 \\
\hline & (11.4) & $(10.5)$ & $(12.7)$ & $(10.0)$ & (12.4) & $(10.5)$ & $(12.0)$ & (6.6) \\
\hline \multirow[t]{2}{*}{2008} & 7104 & 22043 & 8268 & 4549 & 1488 & 38159 & 4195 & 3315 \\
\hline & (12.4) & $(11.6)$ & $(13.2)$ & $(11.5)$ & $(10.7)$ & (11.2) & $(13.5)$ & (7.1) \\
\hline \multirow[t]{2}{*}{2009} & 4823 & 17475 & 6179 & 3715 & 1069 & 35782 & 3458 & 3205 \\
\hline & (12.4) & $(12.6)$ & (14.4) & (11.3) & (12.9) & (13.9) & $(15.0)$ & (8.4) \\
\hline \multirow[t]{2}{*}{2010} & 7232 & 28146 & 9971 & 5477 & 1173 & 50168 & 3908 & 2911 \\
\hline & $(12.9)$ & $(14.1)$ & (16.8) & $(13.5)$ & $(12.0)$ & $(15.1)$ & (12.8) & $(8.9)$ \\
\hline \multirow[t]{2}{*}{2011} & 10138 & 36065 & 12650 & 8176 & 1148 & 57473 & 5121 & 3462 \\
\hline & (13.8) & $(14.5)$ & (16.9) & $(15.0)$ & (9.9) & $(14.9)$ & (13.3) & (9.6) \\
\hline \multirow[t]{2}{*}{2012} & 9954 & 37671 & 14432 & 9565 & 1290 & 62630 & 5867 & 10278 \\
\hline & $(14.5)$ & $(15.3)$ & $(18.0)$ & (16.3) & (10.8) & $(15.4)$ & (13.8) & $(15.9)$ \\
\hline \multirow[t]{2}{*}{2013} & 9625 & 41032 & 15632 & 10363 & 1512 & 67454 & 6805 & 6669 \\
\hline & (12.4) & $(15.6)$ & (19.7) & (17.4) & (12.1) & $(16.1)$ & (15.3) & (12.6) \\
\hline
\end{tabular}

Fuente: Directorio de estadísticas comerciales del Fondo Monetario Internacional. http:/ / elibrary-data.imf.org/finddatareports.aspx?d=33061\&e=170921 Último acceso: 4 de junio de 2014.

Los valores en paréntesis reflejan las importaciones de China como porcentaje del total de importaciones.

* Las importaciones de China a Cuba de acuerdo con registros de socios; el total de la importaciones totales de Cuba provienen de registro de socios y cálculos. 
De manera paralela al Mercosur, los Estados en el extremo meridional de Sudamérica se dieron a la tarea de completar la delimitación de fronteras terrestres y marítimas y alcanzaron acuerdos políticos que disminuyen significativamente el riesgo de disputas interestatales militarizadas. En 1998, con la mediación de Argentina, Brasil, Chile y Estados Unidos se alcanzó un acuerdo fronterizo entre Ecuador y Perú que sigue vigente. De los acuerdos arriba mencionados, el TLCAN ha sido el más exitoso en la obtención de sus objetivos explícitos: al final de la primera década del siglo xxi, el nivel de comercio intrarregional del TLCAN era tres veces superior al del Mercosur, por ejemplo. ${ }^{11}$

Una década después de la caída de la Unión Soviética, la primacía de Estados Unidos prácticamente no era cuestionada, el consenso ideológico y las políticas democrático liberales y orientadas al mercado seguían siendo dominantes, y la acción colectiva en el continente americano se mantenía como norma eficazmente aplicada.

\section{El CRecimiento de China en los mercados mundiales}

A principios del siglo xxI, el mayor impacto sobre el sistema internacional, incluida su estructura en el continente americano, fue el ascenso de China. La transformación por la que el país asiático atraviesa desde finales de la década de 1970 ha mejorado significativamente el bienestar de muchos de sus ciudadanos. Pero China también acabó por modificar los mercados globales. Desde el inicio de este siglo, el incremento del comercio internacional chino tuvo distintas consecuencias en todos los países de América Latina sujetos a estudio en este análisis. Entre los cambios sistémicos en el ámbito internacional, el más duradero y generalizado en lo que va del siglo es el desarrollo de China en los mercados internacionales (y sus efectos en el comercio latinoamericano). Este crecimiento económico sirve para explicar que haya aumentado el campo de acción en el sistema internacional y, de manera más específica, el

${ }^{11}$ Jorge I. Domínguez, "Regional Economic Institutions in Latin America: Politics, Profits, and Peace”, en Miles Kahler y Andrew MacIntyre (comps.), Integrating Regions, Stanford, Stanford University Press, 2013. 
auge económico de los países latinoamericanos en la primera década del segundo milenio con el consiguiente empoderamiento de los Estados de esta región para implementar las políticas nacionales e internacionales de su preferencia.

Entre 1990 y 2000, justo antes de que en 2001 China se sumara a la Organización Mundial del Comercio (OMC), sus exportaciones al mundo aumentaron de 62700 millones de dólares a $249200 \mathrm{mi}$ llones. En 2000, las exportaciones a América Latina ascendieron a 4200 millones de dólares y las correspondientes importaciones a 5100 millones. ${ }^{12}$ La enorme demanda china aumentó la demanda global y, por lo tanto, se incrementó el precio de muchas materias primas que los países latinoamericanos exportaban. Entre 2001 y 2010, la proporción china de importaciones a nivel mundial creció de 10 a $38 \%$ en cobre, de 14 a $65 \%$ en mineral de hierro y de 26 a $56 \%$ en soya. ${ }^{13}$ Así las cosas, China creó un poderoso y benéfico impacto exógeno que impulsó el crecimiento de los exportadores de materias primas en América Latina.

La información sobre el comercio sino-latinoamericano entre 2000 y 2013 aparece en las tablas 1.1 y 1.2. Entre 2000 y 2007 -en vísperas de la profunda depresión económica mundial-, el valor absoluto del comercio entre China y cada uno de estos países latinoamericanos aumentó casi todos los años. En las naciones que nos competen, la proporción de exportaciones e importaciones chinas muestra una variación ligeramente mayor, aunque la tendencia general también es claramente a la alta. Aunque estos incrementos fueron impresionantes en todo el espectro, cabe mencionar particularmente los casos de Brasil (mineral de hierro y soya) y Chile (cobre), cuyas exportaciones a China se multiplicaron por diez entre 2000 y 2007 para sobrepasar los 10000 millones de dólares en 2007. El golpe de la recesión de 2008 y 2009 fue agudo pero breve: las importaciones de China cayeron en cada uno de los países analizados, pero, salvo en Cuba, para 2010 habían

${ }^{12}$ Fondo Monetario Internacional, Direction of Trade Statistics, diversos años. Estas cifras no incluyen el comercio con Cuba.

${ }^{13}$ CEPAL (Comisión Económica para América Latina y el Caribe), Panorama de la inserción internacional de América Latina y el Caribe, 2011-2012, Santiago, 2013, p. 64. 
ya superado los niveles de 2007. Aunque las exportaciones a China de otros países también cayeron durante la crisis, las procedentes de Brasil, México y Perú siguieron aumentando incluso durante los años de la recesión de 2008 y 2009. Para 2010, las exportaciones a China desde todos estos países (a excepción de Cuba) también habían excedido el volumen de 2007.

Desde la perspectiva de 2013, las exportaciones a China alcanzaron su alto histórico en Brasil, Chile, Colombia y México, aunque de 2011 a 2013 el ritmo de crecimiento de la exportación desde Brasil, Chile y México hacia China registró una desaceleración en comparación con las cifras de la década inmediata anterior. Entre 2011 y 2013, Argentina, Perú y Venezuela también sufrieron una baja en el crecimiento de sus exportaciones a China y las exportaciones desde Cuba disminuyeron. En 2013, las importaciones chinas en cada uno de estos países representaban más de $12 \%$ y la cifra más alta -20\%- correspondía a Chile. Las exportaciones de Brasil, Chile, Cuba, Perú y Venezuela a China también alcanzaban $14 \%$ del total de sus exportaciones, siendo las de Chile nuevamente las más altas, con 25\%. En 2013, las exportaciones a China de los ocho países latinoamericanos que aparecen en la tabla 1.1 alcanzaron cerca de 102000 millones de dólares mientras que las importaciones llegaron a 159000 millones de dólares. Las exportaciones de Brasil corresponden a $45 \%$ del total de exportaciones a China de estos ocho países.

La principal nota discordante en esta historia, que en términos generales podría describirse como feliz, se presentó en las relaciones entre México y China. En 2013, el déficit bilateral de México con China alcanzó niveles extremadamente altos, en gran medida, a causa de la estrategia de compañías chinas para acceder al mercado del tLCan. México fue el último de los 141 miembros de la oмc en firmar un acuerdo para autorizar la admisión de China a la Organización. La competencia de China resultó ser real. Para 2003, China había reemplazado a México como el segundo abastecedor más importante en las importaciones de Estados Unidos, y $85 \%$ de la manufactura de calzado en México se había reubicado en el país asiático. Sony, NEC, VTech y Kodak cerraron sus operaciones en México y las trasladaron a China, y doce de los 
veinte sectores económicos fundamentales de la nación latinoamericana que exportaban a Estados Unidos ya se enfrentaban a algún tipo de competencia -en algunos casos significativa- por parte de exportadores chinos. ${ }^{14}$ Una década más tarde, la tendencia más alentadora para México fue el aumento sostenido de los costos de mano de obra en China, que en México se mantenían más o menos constantes. Para 2011, la mano de obra costaba prácticamente lo mismo en ambas naciones. ${ }^{15}$

Las relaciones de China con Venezuela y Cuba indican que los objetivos político ideológicos pudieran desempeñar un papel secundario en la política comercial china. El comercio sino-cubano muestra un déficit en el comercio bilateral de la isla con China cada año. Este déficit comercial fue bajo sólo en 2007 y se ha incrementado significativamente desde 2011. En 2013, Cuba registró el mayor valor de importaciones procedentes de China en lo que va del siglo con un valor tres veces superior al de sus exportaciones a ese país. Sin embargo, China permite a Cuba diferir los pagos de lo que importa. La solidaridad con el único régimen comunista fuera de Asia del Este es el mejor argumento para explicar la tolerancia de China en relación con los déficits cubanos. ${ }^{16}$

El presidente venezolano Hugo Chávez dedicó mucho tiempo a procurar el fortalecimiento de los vínculos de su país con China. En 2005, Chávez impulsó decididamente las importaciones chinas a Venezuela y las exportaciones venezolanas al país asiático finalmente aumentaron en 2007. Un nuevo salto en el comercio bilateral y la subsecuente estabilización de la relación comercial en el alto nivel alcanzado caracterizaron a 2011. Para 2013, Venezuela se había convertido en el tercer exportador latinoamericano a China, aunque, en importaciones, únicamente superaba a Cuba (véase la tabla 1.2). De hecho, el comercio bilateral tardó en estar

14 CEPAL, "Los efectos de la adhesión de China a la omc en las relaciones económicas con América Latina y el Caribe”, Panorama de la inserción internacional de América Latina y el Caribe, 2002-2003, Santiago, unP, 2004, p. 221.

15 CEPAL, Panorama de la inserción, 2012-2012, p. 43.

${ }^{16}$ Para una descripción de un experto chino de la historia de las relaciones bilaterales entre China y Cuba, véase Mao Xianglin, Sobre el socialismo en Cuba, Beijing, China Intercontinental Press, 2013, capítulo XI. 
a la par de las coincidencias políticas, pero, a diferencia de lo que sucede en su relación con Cuba, China no tiene subsidios para Venezuela.

En su segunda gira latinoamericana -que se llevó a cabo en 2014-, el presidente Xi Jinping participó, al lado de Rusia, la India y Sudáfrica, en una reunión cumbre en Brasil, y aprovechó la oportunidad para formular un mensaje integral sobre las relaciones de su país con América Latina. El presidente Xi puso énfasis en la importancia de las relaciones comerciales entre China y varios países de la región y, de manera sorprendente, prácticamente no hizo mención a las inversiones de su país en Latinoamérica. También subrayó las relaciones bilaterales y multilaterales de cooperación dentro del orden internacional existente y, sin mencionar a Estados Unidos, celebró discretamente la existencia y virtudes de una "multipolaridad global". ${ }^{17}$

Así, China amplió, tanto en el ámbito regional como mundial, las oportunidades políticas de América Latina y de otros países, y lo hizo fundamentalmente a través de una prosperidad basada en el comercio y no refutando a Estados Unidos en América Latina, pues ha preferido permitir que la influencia estadounidense implosione por sí misma. En este siglo, la importancia del comercio chino para Latinoamérica ha sido extraordinaria. A pesar de que existe una desaceleración en el crecimiento de las exportaciones latinoamericanas a China desde 2011, los niveles de importación y exportación se han mantenido en los niveles más altos o muy cercanos a su récord histórico. En este caso, las exportaciones cubanas son la única excepción.

Capacidades internacionales mejoradas de AmÉrica Latina EN LA PRIMERA DÉCADA DEL SIGLO XXI

El buen desempeño económico de América Latina entre 2000 y 2007 guarda una importante relación con el aumento del comercio

17 "La larga distancia no borra la íntima amistad", Granma, 14 de julio de 2014, http://www.granma.cu/mundo/2014-07-14/ último acceso: 15 de julio de 2014. 
con China. En esta sección se presenta una de las formas en que la nueva prosperidad financiera de los Estados latinoamericanos más grandes amplió su margen de acción independiente en el ámbito internacional. Sin lugar a dudas, esto es un efecto, en el propio continente americano, del auge chino a nivel mundial.

Desde el fin de la recesión en 2003 hasta el inicio de la siguiente crisis en 2008, el producto interno bruto (PIB) agregado de América Latina creció entre 4.6 y $6.1 \%$ cada año. Durante este periodo, el crecimiento de Argentina, Perú y Venezuela fue significativamente más alto que la media latinoamericana, aunque el de Colombia también estuvo por encima del promedio. Es probable que, del mismo modo, Cuba haya superado la media, pero la información sobre su producto interno bruto es más difícil de interpretar. Brasil, Chile y el conjunto de los países centroamericanos y del Caribe se mantuvieron cerca del promedio latinoamericano, y México, a pesar de no haber alcanzado esa línea, tuvo un crecimiento respetable. En casi toda la región, los РІв nacionales cayeron en 2009, pero, de los ocho países que este estudio abarca, Argentina, Colombia y Perú presentaron crecimiento. Desde 2010, con algunas excepciones, las economías latinoamericanas sí han registrado un crecimiento, aunque su ritmo medio refleja una desaceleración de 5.9 a $2.6 \%$ entre 2010 y 2013. Esta desaceleración ha sido más marcada en Brasil, México y Venezuela. ${ }^{18}$

Como el crecimiento económico de la primera década del siglo xxi se debe, en gran medida, al auge en la exportación, entre 2001 y 2008 la posición financiera internacional de la mayoría de los países latinoamericanos y del Caribe mejoró sustancialmente: en este periodo aumentaron las reservas internacionales de todos los países incluidos en la tabla 1.3. Las reservas internacionales de Brasil se multiplicaron más de cinco veces, las de Perú casi cuatro, las de Argentina y Venezuela se triplicaron, y las de Colombia y México se duplicaron. Tras la crisis financiera de 2008 y 2009, las reservas internacionales de Brasil, México y Perú se incrementaron

18 CEPAL, Anuario estadístico de América Latina y el Caribe, 2008, Santiago, 2009, tabla 2.1.1.1; CEPAL, Balance preliminar de las economías de América Latina y el Caribe, 2013, Santiago, 2014, tabla A-2. 
de manera significativa, las de Colombia lo hicieron modestamente y las de Chile se mantuvieron estables. Las reservas argentinas disminuyeron ligeramente en 2011 y a la mitad en 2013. Venezuela perdió $80 \%$ de sus reservas internacionales entre 2008 y 2013.

TABLA 1.3

Activos de reservas internacionales, 2001-2013

(miles de millones de dólares)

\begin{tabular}{lcccrr}
\hline \multicolumn{1}{r}{ País } & 2001 & 2005 & 2008 & 2011 & 2013 \\
\hline Argentina & 14.6 & 27.3 & 44.9 & 43.3 & 28.3 \\
Brasil & 35.6 & 53.3 & 192.9 & 350.4 & 356.3 \\
Chile & 14.4 & 16.9 & 23.1 & 41.9 & 41.1 \\
Colombia & 10.2 & 14.8 & 23.5 & 31.4 & 42.8 \\
México & 44.8 & 74.1 & 95.1 & 144.2 & 175.6 \\
Perú & 8.7 & 13.7 & 30.3 & 47.3 & 64.5 \\
Venezuela & 9.7 & 24.5 & 33.7 & 10.6 & 6.7 \\
\hline
\end{tabular}

Fuente: Estadísticas financieras internacionales del Fondo Monetario Internacional. http:/ / elibrary-data.imf.org/Query Builder.aspx?key=19784651\&ss=322 Último acceso: 6 de junio de 2014.

Gracias a estas tendencias, los gobiernos de América Latina se volvieron financieramente independientes del Fondo Monetario Internacional (FMI). Como se puede observar en la tabla 1.4, Chile y Venezuela no se han visto obligados a pedir préstamos del FMI en lo que va del siglo, y Cuba nunca lo ha hecho. Brasil y Argentina no han requerido de un acuerdo con el FMI desde 2002 y 2003, respectivamente, y ambos países pagaron su deuda al Fondo antes del año formal de vencimiento, según se reporta en la tabla 1.4. Previo al estallido de la crisis financiera de 2008 y 2009, México y Colombia también obtuvieron excelentes resultados financieros internacionales. De los países que abarca este estudio, sólo Perú siguió dependiendo del financiamiento del FMI, aunque no tuvo problemas para salir avante de las dificultades de 2008 y 2009. Por primera vez en una generación, en la primera década de este siglo, los gobiernos de los principales países latinoamericanos establecieron 
las políticas económicas que, según su propio criterio, más les convenían. El FMI fue relegado y se mantuvo al margen y, por lo tanto, el gobierno de Estados Unidos no pudo utilizar esta ruta indirecta para influir en las políticas económicas de América Latina. (La crisis financiera de 2008 y 2009 obligó a Colombia y México a recurrir nuevamente al apoyo financiero del FMI, pero los gobiernos de estos dos países ya coordinaban sus políticas económicas internacionales de manera cercana con Estados Unidos.)

TABLA 1.4

Años de acuerdos recientes entre el Fondo Monetario Internacional y países latinoamericanos y del Caribe, 1989-2009

\begin{tabular}{lccl}
\hline & $\begin{array}{c}\text { Año del último } \\
\text { acuerdo }\end{array}$ & Expira & \multicolumn{1}{c}{ Tipo } \\
\hline Argentina & 2003 & 2003 & Acuerdo precautorio \\
Argentina & 2003 & 2006 & Acuerdo precautorio \\
Brasil & 2001 & 2002 & Acuerdo precautorio \\
Brasil & 2002 & 2005 & Acuerdo precautorio \\
Chile & 1989 & 1990 & Servicio ampliado del FMI \\
Colombia & 2003 & 2005 & Acuerdo precautorio \\
Colombia & 2005 & 2006 & Acuerdo precautorio \\
Colombia & 2013 & 2015 & Línea de crédito flexible (inicio en 2009) \\
México & 1999 & 2000 & Acuerdo precautorio \\
México & 2012 & 2014 & Línea de crédito flexible (inicio en 2009) \\
Perú & 2004 & 2008 & Acuerdo precautorio \\
Perú & 2007 & 2009 & Acuerdo precautorio \\
Venezuela & 1989 & 1993 & Servicio ampliado del FMI \\
Venezuela & 1996 & 1997 & Acuerdo precautorio \\
\hline
\end{tabular}

Fuente: Acuerdos de préstamo del FMI, http://www.imf.org/external/np/ fin/tad/extarr1.aspx. Último acceso el 5 de junio de 2014.

Para cada país se presentan los dos acuerdos más recientes desde 1989. Chile sólo ha firmado un acuerdo desde 1989.

Al contribuir a que los ingresos de la mayoría de las naciones latinoamericanas aumentaran de manera significativa, China contribuyó también, aunque de manera indirecta, al fortalecimiento 
de las economías de América Latina y, por consiguiente, a la capacidad internacional de los Estados latinoamericanos. En la segunda mitad de la década de 2000, Brasil empezó a desempeñar un papel de liderazgo en América del Sur, lo que en parte se debió a su recién obtenida independencia financiera internacional. De manera similar, Argentina se independizó del FMI y de los prestamistas internacionales, porque, gracias a la exportación de materias primas a China, su economía creció por encima de ocho por ciento todos y cada uno de los años comprendidos entre 2003 y 2007 y nuevamente en 2010 y 2011. El ya fallecido Hugo Chávez supo proyectar su influencia internacional, porque, a consecuencia del auge en los precios del petróleo, Venezuela tuvo una tasa de crecimiento espectacular a mediados de la primera década de nuestro siglo, que le permitió financiar a sus partidarios en América Latina y el Caribe. En los primeros diez años del siglo, las políticas en materia exterior de los distintos gobiernos latinoamericanos adquirieron una independencia nunca antes vista. China se merece un agradecimiento.

Sin embargo, en la segunda década del siglo, la influencia de Chávez se debilitó, no sólo por la enfermedad que lo condujo a la muerte, sino porque las reservas internacionales venezolanas se desplomaron. Del mismo modo, en 2014, y por primera vez en doce años, Argentina se volvió vulnerable ante los acreedores privados internacionales, justo cuando la posición de sus reservas internacionales se había tornado más precaria. Lamentablemente, la desaceleración en el crecimiento de sus exportaciones a China no ayudó nada.

\section{UN EQUILIBRIO ANTE LA INFLUENCIA ESTADOUNIDENSE: EL SISTEMA INTERNACIONAL Y AMÉRICA LATINA EN LA PRIMERA DÉCADA DEL SIGLO XXI}

El segundo cambio en el sistema internacional a principios del siglo xxi fue la nueva respuesta general a la tentativa del gobierno estadounidense de reclamar su primacía global. En los primeros años de la década de 1990, tras el colapso de la Unión Soviética y 
de la Europa comunista, Kenneth Waltz dijo que "la respuesta de los otros países cuando uno de ellos busque u obtenga un poder preponderante será procurar equilibrarlo". ${ }^{19} \mathrm{El}$ pronóstico sistémico general de Waltz no se cumplió durante casi toda la década de 1990, pero fue profético para el decenio inmediato posterior.

La alternativa más aguda a las premoniciones de Waltz data de 1990: el ensayista Charles Krauthammer describió el sistema internacional posterior a la Guerra Fría como "unipolar", es decir, que "el centro del poder mundial es un superpoder no cuestionado: Estados Unidos acompañado por sus aliados occidentales”. Justo antes de la guerra estadounidense contra Iraq, Krauthammer revisó su declaración y afirmó: "el momento unipolar se ha convertido en la era unipolar". El "reto de una unipolaridad de esta naturaleza no procede del exterior" (a diferencia de lo que sostenía Waltz), sino "del interior". Con esta declaración se preguntaba si Estados Unidos sería gobernado por quienes estuvieran dispuestos a participar en "la aplicación agresiva y confiada del poder unipolar". Terminó su artículo parafraseando a Benjamín Franklin: "La historia les ha dado un imperio, si es que lo quieren mantener". ${ }^{20}$

En marzo de 2003, Estados Unidos declaró la guerra a Iraq. El gobierno de Bush afirmaba que el régimen encabezado por el presidente iraquí Saddam Hussein escondía armas nucleares y otras armas de destrucción masiva, conspiraba para apoyar a los terroristas que habían atacado Nueva York y Washington el 11 de septiembre de 2001, cometía crímenes brutales en contra de su propio pueblo, amenazaba a sus vecinos más pequeños y gobernaba al país de manera autoritaria. El senado estadounidense respaldó la decisión del gobierno de Bush de ir a la guerra. En el senado, todos los republicanos, salvo uno, votaron a favor de la ofensiva militar. Lo mismo hizo la mayoría de los demócratas, incluidos John Kerry y Hillary Clinton, quienes más adelante se convertirían en

${ }^{19}$ Kenneth Waltz, "The Emerging Structure of International Politics", en Armand Clesse, Richard Cooper y Yoshikazu Sakamoto (comps.), The International System After the Collapse of the East-West Order, Dordrecht, Martinus Nijhoff, 1994, p. 169.

${ }^{20}$ Charles Krauthammer, "The Unipolar Moment Revisited”, The National Interest, 70, invierno de 2002-2003, pp. 5-17. 
candidatos presidenciales, y John Edwards y Joseph Biden, quienes poco después buscarían la vicepresidencia de la nación.

Con el tiempo, esta decisión de Estados Unidos redimiría el pronóstico de Waltz sobre el sistema internacional. A pesar de sus grandes esfuerzos, Estados Unidos no obtuvo para esta guerra la autorización del Consejo de Seguridad de la Organización de las Naciones Unidas. De cualquier forma, siguieron adelante con el apoyo del Reino Unido, Italia, España y Japón, y ante la oposición de Alemania, Francia, Rusia y Canadá. Para mediados de 2003, había quedado claro que Iraq no tenía armas de destrucción masiva y que no había conspirado para apoyar a los terroristas que habían atacado Nueva York y Washington. El apoyo a la política bélica en Iraq de la administración de Bush disminuyó tanto entre sus aliados como dentro de la Unión Americana. En 2008, el Partido Republicano perdió la presidencia y el control de las dos cámaras del congreso. La "era unipolar" había llegado a su fin.

La decisión de Estados Unidos de ir a la guerra en Iraq dividió a los países latinoamericanos. México, Cuba y la mayoría de los países sudamericanos se opusieron a la determinación estadounidense. Entre los países más grandes, la excepción fue Colombia, que apoyó a Estados Unidos. Muchos de los países más pequeños apoyaron a la Unión Americana con tropas. En agosto de 2003, Honduras y la República Dominicana desplegaron 368 y 302 elementos, respectivamente. Poco después, en septiembre, Nicaragua envió a 230 soldados. Las fuerzas nicaragüenses prestaron servicio en Iraq hasta febrero de 2004 y las hondureñas y dominicanas hasta mayo de ese mismo año. El Salvador resultó ser el aliado más férreo de Estados Unidos en América Latina. Fue el único país de la región que desplegó y mantuvo tropas en Iraq entre 2003 y enero de 2009. En ese periodo, El Salvador rotó a más de 3000 soldados en Iraq: inicialmente envió a 380 y, para la víspera de la repatriación, esta cifra había disminuido a 200 elementos.

En marzo de 2003, dos países de América Latina -Chile y México- ocupaban sendos asientos en el Consejo de Seguridad de la ONU. Ninguno de los dos apoyó la autorización para que la coalición encabezada por Estados Unidos hiciera la guerra contra Iraq (a fin de cuentas, no hubo un voto formal del Consejo de Seguridad de las 
Naciones Unidas porque Estados Unidos y sus aliados retiraron la resolución). Su postura coincidía con la opinión generalizada entre la mayoría de los gobiernos latinoamericanos.

Conforme transcurría el tiempo, la guerra de Iraq generaba una oposición pública mundial más amplia y profunda en contra de las políticas del gobierno de George W. Bush. Las tropas estadounidenses permanecieron en Iraq hasta diciembre de 2011, es decir, durante casi todo el primer periodo del presidente Barack Obama. Pero Estados Unidos también había invadido Afganistán a finales de 2001, tras los ataques terroristas en Nueva York y Washington, y las tropas estadounidenses se mantendrían en aquel país hasta finales de la administración de Obama. Por si fuera poco, la crisis financiera de 2008 y 2009 golpeó severamente la economía de Estados Unidos y privó al gobierno federal estadounidense de recursos para llevar a cabo muchos de sus propósitos, inclusive relativos a la conducción de su política exterior. Con las manos atadas en guerras en Iraq y Afganistán, estancados ante un congreso profundamente dividido y despojado de fondos presupuestales para un gran número de iniciativas, Estados Unidos fue más fácilmente ignorado o confrontado por el mundo entero. A principios del siglo Xxi, la conducta del poder líder en el sistema internacional condujo a su propio debilitamiento tal y como había sucedido años atrás, inmediatamente después de la derrota de Napoleón.

La historia del sistema internacional durante el segundo periodo de George W. Bush y la presidencia de Obama es una historia sobre el exitoso equilibrio respecto a la influencia de Estados Unidos. A mediados de la década de 2010, los intereses estadounidenses estaban en juego ante la extensa guerra en Afganistán, la renovada acción bélica en Iraq, la guerra civil en Siria y, por si fuera poco, el resurgimiento de las fuerzas terroristas en esos países. Estados Unidos no tiene la capacidad -y quizá tampoco la voluntadpara comprometerse total y completamente en esas guerras, del mismo modo que ningún presidente estadounidense posterior a la Guerra Fría redujo de manera significativa las amenazas a la paz regional y mundial que representaban la República Islámica de Irán o la República Popular Democrática de Corea (Corea del Norte). En la segunda década de este siglo, China también se 
volvió mucho más firme y enérgica en sus demandas en torno a zonas marítimas y archipiélagos al sur y al este de su territorio, lo que ha enfurecido a sus vecinos sin que Estados Unidos haya podido hacer mucho más que externar su aflicción.

De la misma manera que el auge en el mercado de materias primas de los primeros años del siglo xxi fortaleció las capacidades de varios países sudamericanos, también vigorizó las capacidades del gobierno de la Federación Rusa, encabezado -directa o indirectamente- por Vladimir Putin. En la década de 1990, tras la caída de la Unión Soviética, el papel de Rusia se tornó desdeñable en gran parte del mundo y, de manera especial, en América Latina. Con el aumento en los precios del petróleo y gas natural, el gobierno ruso reconstruyó sus capacidades, particularmente sus fuerzas armadas. En 2013, Rusia arrebató a Ucrania la Península de Crimea. Salvo por la imposición de una serie de sanciones económicas o de otro tipo a Rusia, Estados Unidos y sus aliados de la Organización del Tratado del Atlántico Norte (OTAN) se mantuvieron al margen, incapaces de hacer algo. En América Latina, durante el último periodo completo de Chávez, Rusia desarrolló una relación activa con Venezuela que incluía la venta de armas y la visita de la marina rusa a puertos venezolanos. Rusia también mejoró sus relaciones con Cuba y le dio la bienvenida al presidente Raúl Castro en su primera visita a Moscú en dos décadas. Además, en julio de 2014, el presidente Putin viajó a la Habana para cancelar noventa por ciento de la antigua deuda cubana con la Unión Soviética, y a Buenos Aires y Brasilia para firmar acuerdos sobre energía nuclear. Ese mismo mes, en el marco de la Copa del Mundo de Brasil, Putin se encontró con el presidente de China, Xi Jinping, y ambos asistieron a una reunión cumbre con los mandatarios de Brasil, la India y Sudáfrica. Además, el mandatario ruso encabezó el lanzamiento de su país como sede del siguiente encuentro mundial de fútbol.

La voluntad de otros países de ignorar u oponerse a Estados Unidos también ha aumentado. En lo que va del siglo, la unión americana no ha logrado conseguir apoyos que favorezcan sus puntos de vista en temas como un nuevo acuerdo de comercio internacional dentro de la Organización Mundial del Comercio, el 
cambio climático, la oposición a la Corte Penal Internacional, los problemas de energía internacional, los esfuerzos para aislar a los gobiernos de Cuba, Rusia, Venezuela o Zimbabue. En 2014, Narendra Modi, a quien el gobierno estadounidense había negado desde hacía tiempo una visa por apoyar el genocidio, fue electo primer ministro de la India.

El debilitamiento de la influencia estadounidense a nivel mundial favoreció a los Estados latinoamericanos cuando desafiaban a Estados Unidos, incluso en temas que eran fundamentales para el gobierno estadounidense. Así las cosas, Chile y México no fueron los únicos que se oponían a Estados Unidos en el Consejo de Seguridad de las Naciones Unidas en el tema de la guerra contra Iraq, pues contaban con el apoyo de otros aliados de ese país. México también discrepaba de Estados Unidos en asuntos migratorios. Brasil abrazó nuevas iniciativas en materia de política exterior de la misma manera que Francia, Sudáfrica y la India lo hacían en áreas de su respectivo interés. El gobierno estadounidense difería de los puntos de vista del gobierno brasileño sobre cómo responder a la expropiación de concesiones de gas natural en Bolivia en 2006 y respecto a la (pequeña) amenaza de seguridad que representaba la actividad criminal transnacional en la frontera tripartita entre Brasil, Argentina y Paraguay. El presidente venezolano Chávez fue quien más retó a Estados Unidos.

Los Estados latinoamericanos rediseñaron la arquitectura regional de organizaciones internacionales en el Hemisferio Occidental con la creación de tres nuevas instituciones multilaterales y con la exclusión de Estados Unidos en cada una de ellas. La Unión de Naciones Suramericanas (Unasur), lanzada oficialmente en 2008, se remontaba a 2004, cuando vio la luz la Comunidad de Naciones Suramericanas. La Unasur fue la expresión multilateral de un interés del presidente Lula da Silva de Brasil de crear un marco institucional que permitiera a su país convertirse en líder de América del Sur. También en 2004, Venezuela y Cuba dieron a conocer la Alianza Bolivariana para los Pueblos de Nuestra América (ALBA), organización financiada por Venezuela a la que Cuba dotó de personal "solidario" que prestaba, entre otros, servicios de salud en varios países. La mayoría de sus miembros son pequeños 
países latinoamericanos (Bolivia, Ecuador, Nicaragua) o países anglófonos del Caribe y Surinam. La Comunidad de Estados Latinoamericanos y Caribeños (CELAC) inició operaciones en diciembre de 2011. Los primeros tres países que lo presidieron fueron Venezuela, Chile y Cuba. Esta organización apenas institucionalizada, sin fondos ni personal suficientes, ofrece un espacio provechoso para atender inquietudes comunes. En 2008, la Unasur ayudó a aliviar las tensiones de una grave crisis política en Bolivia y, en 2010, tras un conflicto militar, sirvió como mediador entre Colombia, por un lado, y Venezuela y Ecuador, por el otro. ${ }^{21}$ El relativo desinterés estadounidense en el multilateralismo regional y la subfinanciación de su obligación financiera ante la Organización de Estados Americanos ${ }^{22}$ facilitó su propia marginalización en el continente americano.

En el ámbito de la política exterior, la mayoría de los países latinoamericanos demostró una independencia que no se había visto desde la década de 1970, si acaso. Se sentían seguros de participar en la búsqueda de un "equilibrio suave" respecto a Estados Unidos y, por lo tanto, ampliaron el margen de su autonomía internacional. No cabe duda de que el comportamiento estadounidense propició esa actitud.

\section{EL DESMORONAMIENTO DEL CONSENSO IDEOLÓGICO INTERAMERICANO EN LA PRIMERA DÉCADA DEL SIGLO XXI}

En la década de 1990 se desarrolló en América Latina un consenso democrático en favor del mercado que dependía de instituciones internacionales para la conducción de la política exterior. Ese consenso fracasó en la primera década del siglo xxı, lo que no significa

${ }^{21}$ Para un análisis general, véase Natalia Saltalamacchia Ziccardi, "Regional Multilateralism in Latin America: unASur, ALbA, and CELAC", en Jorge I. Domínguez y Ana Covarrubias (comps.), The Handbook of Latin America in the World, Nueva York, Routledge, 2015.

22 Thomas Legler, "Beyond Reach? The Organization of American States and Effective Multilateralism”, en Jorge I. Domínguez y Ana Covarrubias (comps.), The Handbook of Latin America in the World, Nueva York, Routledge, 2015. 
que se haya sustituido con otro; por el contrario, surgió una polarización ideológica más amplia. También el gobierno de Estados Unidos contribuyó a esta situación.

El presidente de Venezuela Hugo Chávez encabezó el ataque en contra del consenso ideológico liberal. De manera contundente, reafirmó el papel del Estado en la economía venezolana y subrayó que el principio fundamental de legitimización era la democracia mayoritaria y no un constitucionalismo liberal con la capacidad de contener el poder presidencial para proteger los derechos de las minorías políticas. Así, los medios de comunicación masiva, el parlamento nacional, la suprema corte y otros organismos estatales, hasta entonces independientes, vieron cómo se restringía su autonomía. Chávez fue reelecto en varias ocasiones, cambió la Constitución una y otra vez, y gastó con generosidad para implantar el dominio de su mayoría. Unidos por el dogma de que a los presidentes democráticamente electos los respalda una legitimidad que está por encima de jueces cuyos nombramientos no han pasado por las urnas o de parlamentarios que representan unidades subnacionales, los mandatarios Evo Morales de Bolivia, Rafael Correa de Ecuador y Daniel Ortega de Nicaragua siguieron, en mayor o menor medida, el ejemplo de Chávez. También el presidente colombiano Álvaro Uribe creía en su propia e irrepetible legitimidad democrática, aunque acabó por ceder ante la Corte Constitucional de Colombia cuando ésta determinó prohibir una tercera reelección presidencial consecutiva.

Las preferencias en temas de política económica mostraron ser aún más heterogéneas. ${ }^{23}$ Varios de los gobiernos clave de la región-Chile, Colombia, México, Perú- mantuvieron sus políticas a favor del mercado. También Brasil, aunque las administraciones de Lula da Silva y Dilma Rousseff subrayaron el papel del Estado en la economía con mayor énfasis que su predecesor, Fernando Henrique Cardoso. En 2012, el gobierno argentino renacionalizó la

${ }^{23}$ Para un análisis de los cambios en las preferencias en temas de política económica, véase Javier Corrales, "The Backlash against Market Reforms in Latin America”, en Jorge I. Domínguez y Michael Shifter (comps.), Constructing Democratic Governance in Latin America, $3^{\mathrm{a}}$ ed., Baltimore, The Johns Hopkins University Press, 2008. 
industria petrolera, confiscándosela a la empresa española Repsol. ${ }^{24}$ Este acto fue la culminación de una serie de políticas que incluyeron la morosidad en el pago de la deuda internacional del país y la reprogramación de ciertos pagos de esa deuda, así como la ampliación del papel del Estado en distintos sectores de la economía. A principios del siglo, Bolivia padeció una revolución social que condujo, en mayo de 2006, al embargo soberano de las reservas de gas natural y a la renegociación, bajo coerción, de pagos de las compañías operantes al Estado boliviano. Venezuela no había liberalizado demasiado su economía, pero el presidente Chávez aumentó significativamente la regulación estatal en este campo y renacionalizó algunas empresas importantes que se habían privatizado a finales del siglo inmediato anterior. Chávez se convirtió en el vocero más visible del resentimiento de quienes se habían sentido abandonados, oprimidos o desdeñados por gobernantes anteriores y por el gobierno de los Estados Unidos de América.

El consenso liberal de la década de 1990 -hay que reconocerlotenía fallas importantes. México había sido un modelo del impulso hacia políticas económicas "liberales" en favor del mercado, pero, desde el punto de vista político, seguía bajo un régimen autoritario cuyas elecciones no gozaron de credibilidad sino hasta casi el final del siglo xx. Las políticas económicas de los presidentes Carlos Menem (Argentina) y Alberto Fujimori (Perú) también eran liberales. Fujimori encabezó un golpe de Estado en 1992 en contra del congreso y la corte suprema peruanos, y gobernó de manera autoritaria a pesar de haber sido reelecto en 1995. Por su parte, Menem también logró reafirmar su poder a través de una reelección democrática, pero su trato tanto con la corte suprema como con el congreso de su país puede ser descrito como imperioso.

El desmoronamiento del consenso ideológico interno en la primera década del milenio tuvo implicaciones internacionales. Cabe destacar, de manera evidente, la disminución de la eficacia de la Organización de Estados Americanos para llevar a cabo la tarea de defender la democracia constitucional liberal. La oEA

${ }^{24}$ Noel Maurer y Gustavo Herrero, "YPF - The Argentine Oil Nationalization of 2012”, Harvard Business School Case, 26 de junio de 2013. 
funcionaba a través del consenso de sus miembros, y el consenso se había hecho añicos. Cuando la Organización intentó mediar entre los rivales nacionales dentro de Venezuela, lo único que logró fue encolerizar al presidente Chávez, conque Venezuela dejó de invitar a la OEA a observar sus elecciones. Hubo una marcada reincidencia en el autoritarismo tras la victoria de Chávez en el referendo presidencial de 2004, y lo mismo sucedió en Ecuador a partir de 2007 y en Nicaragua después de 2009. La respuesta internacional para revertir estas tendencias contrarias al liberalismo constitucional fue casi nula. La oEA también quiso revertir el golpe de Estado de 2009 en Honduras, pero sus esfuerzos fueron en vano. ${ }^{25}$

Las nuevas instituciones multilaterales creadas por gobiernos de América Latina en el nuevo siglo (véase la sección anterior) no tienen ningún compromiso con la defensa de regímenes democráticos, lo que representa una clara diferencia en relación con la Organización de Estados Americanos. Cuba no sólo es miembro de Celac, sino que Raúl Castro la ha presidido. La ALBA es una creación conjunta de Venezuela y Cuba. La Unasur no tiene ninguna cláusula sobre democracia. Un debilitamiento similar en el compromiso con la democracia constitucionalista liberal se hizo evidente cuando Venezuela fue invitada a sumarse al Mercosur, organismo que había incluido una disposición que exigía fidelidad democrática y que había funcionado de manera exitosa en repetidas ocasiones para evitar un regreso al autoritarismo en Paraguay. Sin embargo, el Mercosur dio la bienvenida al gobierno de Chávez a pesar de su trayectoria hacia el autoritarismo. ${ }^{26}$

El gobierno de Estados Unidos contribuyó a que se rompiera el consenso ideológico. Tal parece que la administración de George W. Bush o bien apoyó los esfuerzos para derrocar al presidente

25 Thomas Legler, "Demise of the Inter-American Democracy Promotion Regime?”, en G. Mace, A. Cooper y T. Shaw (comps.), Inter-American Cooperation at a Crossroads, Nueva York, Palgrave MacMillan, 2011.

${ }^{26}$ Para un análisis sobre el debilitamiento del compromiso internacional en la defensa de las instituciones democráticas, véase Laurence Whitehead, "The Fading Regional Consensus on Democratic Convergence", en Domínguez y Shifter (comps.), op. cit. 
electo democráticamente en Venezuela en 2002, Hugo Chávez, o bien fue verdaderamente inepto para transmitir la idea contraria. A fin de afectar los resultados, la administración de Bush también interfirió en las elecciones presidenciales de Bolivia (2003, 2005), El Salvador (2004) y Nicaragua (2006). Lo anterior obviamente empañó las credenciales democráticas del gobierno estadounidense y dañó severamente su credibilidad interamericana. A pesar de haberse opuesto públicamente al golpe de Estado de 2009 en Honduras, la administración de Obama tampoco logró inyectar al proceso la fuerza necesaria para revertirlo.

Durante las administraciones de Bush y Obama, el gobierno de Estados Unidos también mantuvo las antiguas prácticas de subsidio a los productores agrícolas estadounidenses. Estados Unidos y la Unión Europea no llegaron a un acuerdo para dotar de mayor fuerza a la Organización Mundial del Comercio. Estados Unidos dio la espalda a acuerdos mundiales e incluso hemisféricos y, en cambio, prestó mayor atención a acuerdos bilaterales (Perú, Panamá, Colombia) o minilaterales (por ejemplo el Tratado de Libre Comercio entre Estados Unidos y Centroamérica, CAFTA, por sus siglas en inglés) en los que puede ejercer una mayor influencia, particularmente sobre los socios comerciales más débiles, y proteger su agricultura de una exposición al libre comercio. ${ }^{27}$ En la reunión de ministros de comercio internacional del continente americano, celebrada en Miami en el otoño de 2003, Estados Unidos y Brasil presentaron una propuesta que, para fines prácticos, aniquiló el proyecto de un Área de Libre Comercio de las Américas (ALCA), mismo que había surgido inicialmente durante las presidencias de George H. W. Bush y William J. Clinton. Tras la Cumbre Interamericana de Mar del Plata (2005), los jefes de Estado profundizaron en la ruptura del consenso en torno al libre comercio interamericano, lo que cerró las posibilidades de un acuerdo de libre comercio continental.

A diferencia de los temas analizados en las secciones anteriores, el desmoronamiento del consenso ideológico interamericano

${ }^{27}$ Para un análisis, veáse Nicola Phillips, "U.S. Power and the Politics of Economic Governance in the Americas", Latin American Politics and Society, vol. 47, núm. 4, invierno de 2005, pp. 1-25. 
no se tradujo en un cambio en el sistema internacional en su conjunto pero sí resultó decisivo en el sistema de relaciones internacionales del Hemisferio Occidental: dificultó la coordinación internacional; logró despojar de cualquier atractivo que hubieran podido tener a los valores compartidos como base para la acción común y la resolución de conflictos; fomentó el surgimiento de muchas disputas bilaterales entre Estados sudamericanos. ${ }^{28}$ Este desmoronamiento del consenso ideológico también es uno de los efectos negativos de las políticas del gobierno de Bush, pues su administración contribuyó a la tendencia cada vez más frecuente en América Latina de que los gobiernos actuaran en oposición a las preferencias estadounidenses.

\section{LA CONFIANZA Y LA SEGURIDAD EN LAS RELACIONES ENTRE}

Estados Unidos y América Latina

A finales de noviembre de 2010, la organización no gubernamental WikiLeaks empezó a publicar el contenido de cables diplomáticos estadounidenses que hasta entonces se habían mantenido con carácter confidencial. Entre los documentos que salieron a la luz, apareció una evaluación profesional de gran franqueza escrita por el embajador de Estados Unidos en México, Carlos Pascual, sobre los conflictos internos y las envidias entre las fuerzas de seguridad mexicanas. Esta visión contrastaba con el aplauso público que el gobierno estadounidense daba a las políticas mexicanas de lucha contra el narcotráfico y ocasionó el enojo del presidente de México, Felipe Calderón, quien dejó en claro que ya no podría trabajar con el diplomático estadounidense. Pascual tomó una decisión de principio; lo único que había hecho era cumplir con la tarea de informar a su gobierno, pero no quiso poner en riesgo las relaciones entre los dos países y renunció. Fue

${ }^{28}$ Véase Carlos Pérez Llana, "Modelos políticos internos y alianzas externas", en Ricardo Lagos (comp.), América Latina: ¿Integración o fragmentación?, Buenos Aires, Edhasa, 2008. 
la única baja que, a nivel de embajador, ocasionó la filtración de WikiLeaks. ${ }^{29}$

En junio de 2013, Edward Snowden, quien había sido contratista para la Agencia de Seguridad Nacional de los Estados Unidos (NSA, por sus siglas en inglés), empezó a divulgar miles de documentos clasificados de su país. Entre ellos, había pruebas de que la NSA había empezado a espiar al mandatario mexicano Enrique Peña Nieto cuando todavía era candidato presidencial y que también había tenido acceso a comunicaciones entre la presidenta de Brasil Dilma Rousseff y sus más importantes asesores y colaboradores. En protesta, Rousseff pronunció un virulento discurso ante la Asamblea General de las Naciones Unidas en septiembre y canceló la que hubiera sido su primera visita de Estado a la Casa Blanca.

Aun cuando la difusión no autorizada de estos documentos secretos de Estados Unidos tuvo un efecto a nivel mundial, cabe destacar su impacto dentro del propio continente americano. Muchos embajadores estadounidenses podrían haber renunciado, aunque sólo lo hizo el representante ante el gobierno de México. El espionaje de la NSA fue mucho más generalizado en China y Rusia que en Brasil, pero la respuesta de esos dos países fue relativamente leve. Las prácticas estadounidenses no generaron mayores quejas por parte de gobiernos autoritarios, pues ellos mismos suelen ser más intrusivos en la búsqueda de información. La canciller alemana Angela Merkel estaba molesta porque sus comunicaciones privadas también hubieran sido blanco de la NSA, pero el enojo de Brasil sobrepasó a los demás. Los mandatarios de México, Felipe Calderón, y de Brasil, Dilma Rousseff, eran presidentes democráticos que, a fin de cuentas, habían confiado en el gobierno de Estados Unidos y, de manera particular, en su presidente. Estas filtraciones empañaron las relaciones tanto entre los gobiernos como entre los jefes de Estado.

Estas revelaciones tenían su primer origen en los albores del siglo Xxi cuando Estados Unidos puso énfasis en la búsqueda de

${ }^{29}$ Véase un recuento de los hechos en The Huffington Post, 24 de marzo de 2011, en http://www.huffingtonpost.com/2011/03/24/ último acceso: 13 de julio de 2014. 
información de inteligencia, misma que las innovaciones tecnológicas habían facilitado ampliamente. Tras los ataques terroristas del 11 de septiembre de 2001, Estados Unidos entabló una guerra en contra de los terroristas en todo el mundo, aunque particularmente en Afganistán e Iraq. Para apoyar estos esfuerzos múltiples, el gobierno incrementó y mejoró sus operaciones y capacidades para recabar información y cambió el foco de muchas de sus políticas para centrarlo en temas de seguridad, lo que le ocasionó algunos costos, como la pérdida de confianza por parte de los mandatarios de México y Brasil.

Esta atención redirigida hacia el terrorismo y la guerra también alejó a los presidentes Bush y Obama de América Latina. Bajo ninguna de sus administraciones cruzó la frontera hacia Estados Unidos un terrorista avecindado en Latinoamérica. Cuando las inquietudes sobre seguridad no eran primordiales en una relación bilateral específica (por ejemplo la de Estados Unidos y Argentina), el gobierno estadounidense le prestaba cada vez menor atención. Por el contrario, cuando en la relación bilateral había un tema de seguridad -por menor que fuera, como la preocupación estadounidense de que se traficara y lavara dinero a través de Paraguay-, ese tema se convertía en el centro de la política estadounidense en torno a esa relación bilateral específica. Y para los vecinos cercanos en el Caribe, América Central, Colombia y México, la obsesión estadounidense con el terrorismo y la delincuencia se convirtió en un elemento dominante en su relación con Estados Unidos. ${ }^{30}$ Estados Unidos "veía" esas relaciones bilaterales a través del lente de la seguridad. ${ }^{31}$

${ }^{30}$ Para un análisis que muestre el impacto geográficamente diferenciado de las políticas estadounidenses de seguridad en todo el hemisferio, véase Raúl Benítez Manaut y Arturo Sotomayor, "El dilema mesoamericano: entre la inseguridad externa y la vulnerabilidad interna”, Mónica Hirst, "Seguridad en América del Sur: La dimensión regional de sus desafíos políticos”; y Francisco Leal Buitrago, "Una mirada a la seguridad en la región andina", todos en Ricardo Lagos (comp.), América Latina: ¿integración o fragmentación?, Buenos Aires, Edhasa, 2008.

${ }^{31}$ Para mayores detalles, véase Francisco Rojas Aravena (comp.), La seguridad en América Latina pos 11 de Septiembre, Caracas, Nueva Sociedad, 2003; y Wolf Grabendorff, La seguridad regional en las Américas, Bogotá, Fondo Editorial CREC, 2003. 
El apoyo militar y policiaco de Estados Unidos a los gobiernos de América Latina se duplicó durante la administración de George W. Bush. Aproximadamente la mitad del monto de esta ayuda se destinó a Colombia. Bolivia, Perú y México también recibieron un respaldo importante. Por lo general, la motivación detrás de esta cooperación fue la lucha contra el tráfico de drogas, pero en el caso colombiano también se utilizó para contraatacar las distintas insurgencias. Hasta finales del siglo xx, el gobierno estadounidense había financiado las operaciones del gobierno de Colombia en contra del narcotráfico, pero no en contra de los insurgentes. En el siglo xxi, en cambio, Estados Unidos amplió el alcance de su asistencia de tal manera que sirviera para ambas acciones. ${ }^{32}$

El presidente mexicano, Felipe Calderón, anunció en diciembre de 2006 -poco después de haber tomado posesión- que se desplegaría al ejército mexicano en contra de los cárteles del narcotráfico. En una reunión celebrada en Mérida en marzo de 2007, los mandatarios Felipe Calderón y George W. Bush acordaron la Iniciativa Mérida, según la cual, a fin de que se implementara esta política, Estados Unidos transferiría importantes recursos militares y económicos a México y a países centroamericanos (donde más adelante escalarían los niveles de violencia criminal). Para finales de ese año, los dos gobiernos habían convenido en un paquete de tres años por un monto de 1400 millones de dólares. Transcurrido el año fiscal 2012, el congreso estadounidense había asignado 1900 millones de dólares a la Iniciativa Mérida. ${ }^{33}$ Sin embargo, los desembolsos fueron lentos y el progreso, todavía más.

32 Adam Isacson, Joy Olson y Lisa Haugaard, Below the Radar: U.S. Military Programs with Latin America, 1997-2007, Washington, Latin America Working Group Education Fund, Center for International Policy y Washington Office for Latin America, 2007.

${ }^{33}$ Lisa Haugaard, Adam Isacson y Jennifer Johnson, A Cautionary Tale: Plan Colombia's Lessons for U.S. Policy Toward Mexico and Beyond, Washington, Latin America Working Group Education Fund, Center for International Policy y Washington Office for Latin America, 2011; Departamento de Estado de los Estados Unidos, Oficina para asuntos del Hemisferio Occidental, U.S. Relations with Mexico: Fact Sheet (2013), http://www.state.gov/r/pa/ei/bgn/35749.htm último acceso: 18 de julio de 2014. 
A partir de 2000, los únicos dos proyectos estadounidenses significativos en América Latina eran el Plan Colombia y la Iniciativa Mérida. Por lo tanto, las relaciones entre Estados Unidos y Latinoamérica se aseguraron, ya fuera porque incluían temas de seguridad y violencia significativa o porque no había mucho más en lo que el gobierno de Estados Unidos participara. Así, el turismo, el comercio, la inversión y otras transacciones privadas fueron las que dieron forma a las relaciones bilaterales. El fortalecimiento de las relaciones de seguridad de Estados Unidos terminó por opacar sus relaciones con América Latina.

\section{Las respuestas de América Latina}

Los países latinoamericanos se han diferenciado en sus respuestas a Estados Unidos y en su posición en el sistema internacional, pero hay tres visiones que resumen todo este espectro. La primera es la más fácil de describir. Se trata del eslogan histórico de Fidel Castro, patria o muerte. Para defender su propio concepto de una soberanía cubana sin fisuras, el presidente Castro estaba dispuesto a sacrificar cualquier otra meta posible en materia de política exterior. La debilidad objetiva de Cuba implicaba que invertiría para después sobre invertir todos los recursos necesarios a fin de que la disuasión desafiante pudiera ser una política viable en contra de Estados Unidos.

Otra visión aparece en la primera oración de la obra clásica de Mario Ojeda, Alcances y límites de la política exterior de México. Ojeda explica la política exterior mexicana no como una expresión peculiar de la historia nacional, sino como una política exterior similar a la de cualquier país débil. Desde luego que el autor podría sacar a relucir su impresionante conocimiento sobre el impacto de la historia nacional en la política exterior del país, pero la fuerza de su obra, cuatro décadas después de haber sido escrita, proviene del enfoque disciplinado de realismo internacional que lo caracteriza. Ojeda nos recuerda que México no se quedó al margen del fenómeno de la construcción de la hegemonía estadounidense a consecuencia del fin de la Segunda 
Guerra Mundial. Por el contrario, en su situación de país débil, México debe -de manera pragmática- hacer malabares para combinar sus intereses nacionales con la realidad de la política internacional y con su proximidad a Estados Unidos. Más adelante, Ojeda formula una norma operativa para guiar las relaciones entre estos dos países: Estados Unidos reconoce y acepta la necesidad de México de discrepar de la política estadounidense en cualquier asunto que resulte fundamental para México, incluso si es importante pero no fundamental para Estados Unidos. Por su parte, México coopera en cualquier asunto que resulte fundamental o simplemente importante para Estados Unidos, aunque no lo sea para México. ${ }^{34}$

Un tercer punto de vista surge de la obra de Luciano Tomassini, quien discrepaba de la perspectiva de que "los países latinoamericanos vivieron en un escenario internacional jerarquizado y restrictivo" como "patio trasero" de Estados Unidos. Por el contrario -argumentaba-, el sistema internacional ha cambiado desde la década de 1970 "dando lugar a un escenario internacional más complejo, fluido y dinámico, más fragmentado pero también más interdependiente y, sobre todo, más turbulento y más incierto". Junto con los "procesos de apertura política, económica y financiera internacional” en América Latina, cambió el nivel de participación de los países de la región en el sistema internacional. Se diversificaron las agendas, los actores y los recursos internacionales. Por eso, Tomassini acogió los enfoques "postmodernistas" en el análisis de las relaciones internacionales para cuestionar la sabiduría y las prácticas heredadas y obligar a un replanteamiento de la experiencia histórica. Además, subrayó un enfoque posibilista para el diseño de políticas en materia internacional por parte de los países latinoamericanos. ${ }^{35}$ Conforme las economías latinoamericanas

${ }^{34}$ Mario Ojeda, Alcances y límites de la política exterior de México, México, El Colegio de México, 1976, pp. 3, 26, 79, 93. Para un análisis más profundo de la obra de Ojeda, véase Gustavo Vega Cánovas (comp.), Alcances y límites de la política exterior de México ante el nuevo escenario internacional: Ensayos en honor de Mario Ojeda, México, El Colegio de México, 2009.

${ }^{35}$ Luciano Tomassini, La política internacional en un mundo postmoderno, Buenos Aires, Grupo Editor Latinoamericano, 1991, citas de la p. 241. 
se colapsaban en la década de 1980, Tomassini parecía estar en lo correcto en su caracterización de una situación de mayor turbulencia e incertidumbre. Pero la consecuencia fue un contexto internacional incluso más "restrictivo" en los niveles más bajos de la jerarquía financiera internacional. De manera similar, la década de 1990 se caracterizó por el cambio, pero también por la acrecentada supremacía de Estados Unidos tras la caída de la Unión Soviética. De cualquier forma, las observaciones de Tomassini parecen ser válidas hoy en día cuando, con un sistema económico y político transformado, su marco de análisis abre nuevamente preguntas añejas sobre el impacto en América Latina del más amplio sistema internacional.

Más recientemente, Roberto Russell y Juan Gabriel Tokatlian resumieron las dos lógicas detrás del comportamiento estratégico de los gobiernos latinoamericanos. Una es la lógica de la autonomía. Esta lógica busca contener el impacto de las fuerzas externas, particularmente, las que provienen del gobierno de Estados Unidos. Además, busca diversificar las relaciones internacionales, valora el regionalismo y confía en las instituciones multilaterales. La segunda es la lógica de la aquiescencia. Ésta acepta la primacía de Estados Unidos e intenta utilizarla para alcanzar prosperidad económica. Se sube al tren estadounidense, privilegia los acuerdos bilaterales o minilaterales y considera que el mundo es una serie de oportunidades y restricciones derivadas de su relación particular con Estados Unidos. ${ }^{36}$ Russell y Tokatlian hicieron una buena apreciación de los enfoques contemporáneos, aunque también hacen notar que cada una de las lógicas tiene sus propias variaciones.

Si se recurre a Tomassini como guía para una serie de opciones creativas en las lógicas que, de manera acertada, esbozaron Russell y Tokatlian, la perspectiva de Mario Ojeda sigue vigente. Ojeda nunca se subió al carro de la popularidad de Estados Unidos. Su realismo estaba arraigado en la importancia de limitar el poder estadounidense sobre México, lo que no quiere decir que pensara

${ }^{36}$ Roberto Russell y Juan Gabriel Tokatlian, "Grand Strategy", en Jorge I. Domínguez y Ana Covarrubias (comps.), Handbook of Latin America in the World, Nueva York, Routledge, 2014. 
que México o cualquier otro "país débil" pudieran cerrar los ojos ante el papel de Estados Unidos en el sistema internacional. Ojeda publicó su libro en 1976. Recordemos esa época: en 1974, el presidente estadounidense renunció a su cargo frente a la amenaza de incapacitación por el congreso; en 1975 cayó Saigón, la derrota de Estados Unidos en Vietnam era total; a mediados de la década de 1970, la economía estadounidense estaba hundida en la estanflación en la estela que dejó la primera crisis energética. Ojeda sabía que Estados Unidos era un país poderoso incluso bajo un mal gobierno y con una economía fuertemente golpeada. Su percepción es aplicable también en la actualidad.

\section{Conclusiones}

En los dos últimos siglos, la estructura del sistema internacional cambió dramáticamente tres veces y surgió, asociado al cambio, un consenso ideológico para justificar la intervención internacional de los poderes más fuertes en los asuntos internos de los más débiles. En cada ocasión, el poder líder debilitó su propia primacía temporal y ayudó a destruir el consenso ideológico. Las dos décadas posteriores al colapso de la Unión Soviética dan muestra de estas circunstancias, mismas que ya habían sido observadas con anterioridad a raíz de la caída de Napoleón y que se habían replicado, si bien no con toda exactitud, al final de la Segunda Guerra Mundial. Cabe hacer notar que la primacía de Estados Unidos era mayor en 1990 que en 1945 o que la del zar en 1814, y que, en 1990, el consenso ideológico parecía más sólido que nunca antes. Sin embargo, la influencia dominante de Estados Unidos se desvaneció, lo que no significa hayan desparecido también las enormes capacidades estadounidenses, que evidentemente perduraron.

Este desencadenamiento de la situación tiene distintos pilares. El ascenso de China en los mercados mundiales creó oportunidades de crecimiento para las economías de América Latina, lo que a su vez permitió que en el ámbito de su comportamiento internacional, la mayoría de los gobiernos de la región tuvieran mayor seguridad en sí mismos y fueran más independientes. 
Estados Unidos y China corrigieron el rumbo de sus relaciones políticas en el siglo xxi y, por lo tanto, la mejoría de las relaciones entre América Latina y el país asiático no se logró a expensas de la relaciones con la Unión Americana. El nuevo papel que China desempeñaba en el comercio internacional hizo que se pensara que Estados Unidos había perdido importancia en la economía mundial, por lo que, entre otras razones, merecía una deferencia menor.

El comportamiento del gobierno de Estados Unidos durante la presidencia de George W. Bush, su conducción de la Guerra en Iraq, así como su desprecio por las instituciones internacionales y la consulta diplomática ocasionaron un ambiente internacional propicio para que se hicieran esfuerzos por "equilibrar" el poder estadounidense. Algunos gobiernos lo hicieron con suavidad y otros con mayor energía (Rusia, Irán y Venezuela, por ejemplo). Para cuando terminó la administración de Bush, el reclamo estadounidense de primacía y deferencia ya no era creíble en el continente americano. Las comprensibles distracciones internacionales de Barack Obama y su inhabilidad para trabajar con el congreso contribuyeron poco para restaurar esa credibilidad. La era de la coordinación entre Estados Unidos y América Latina floreció y desapareció en la década de 1990. Las capacidades que se habían visto incrementadas gracias al crecimiento económico latinoamericano, el aislamiento autoinflingido de la administración de Bush y la volatilidad de la administración de Obama fueron factores que suscitaron que las políticas de América Latina en materia exterior gozaran de una autonomía más marcada en relación con Estados Unidos. Ése fue el fin de la unipolaridad.

Igualmente significativa fue el desmoronamiento del consenso "liberal" a favor de la democracia constitucional y los mercados. Este cambio fue pronunciado en el continente americano. También implicó una reducción en la eficacia de las instituciones internacionales en el campo de la coordinación política. Hubo otro cambio, el impacto de las políticas estadounidenses de seguridad hacia América Latina, que -sin haber tenido mayor éxito en ninguna parte- en algunos casos provocó la pérdida de confianza y en otros acrecentó el estado de alerta. 
Sin lugar a dudas, otros factores relativos a los contextos, políticas, oportunidades y personalidades específicos también dan forma al curso que siguen las relaciones bilaterales entre Estados Unidos y cualquier país latinoamericano en particular. Sin embargo, estos cambios sistémicos o cuasisistémicos más amplios resultan fundamentales, pues transformaron las relaciones internacionales del Hemisferio Occidental en los primeros veinticinco años posteriores a la caída de la URSS.

\section{Traducción de Gonzalo Celorio Morayta}

\section{BibliogRAFíA}

Benítez Manaut, Raúl y Arturo Sotomayor, "El dilema mesoamericano: Entre la inseguridad externa y la vulnerabilidad interna”, en Ricardo Lagos (comp.), América Latina: ¿Integración o fragmentación?, Buenos Aires, Edhasa, 2008, pp. 419-458.

Blasier, Cole, The Giant's Rival: The USSR and Latin America, edición revisada, Pittsburgh, University of Pittsburgh Press, 1985.

, The Hovering Giant: U.S. Response to Revolutionary Change in Latin America, edición revisada, Pittsburgh, University of Pittsburgh Press, 1985.

Carothers, Thomas, In the Name of Democracy: U.S. Policy toward Latin America in the Reagan Years, Berkeley, University of California Press, 1991.

Comisión Económica para América Latina y el Caribe (CEPAL), "Los efectos de la adhesión de China a la omc en las relaciones económicas con América Latina y el Caribe", en Panorama de la inserción internacional de América Latina y el Caribe, 2002-2003, Santiago, unP, 2004, pp. 203-219. , Anuario estadístico de América Latina y el Caribe, 2008, Santiago, CEPAL, 2009.

— 2011-2012, Santiago, 2013.

— Balance preliminar de las economías de América Latina y el Caribe, 2013, Santiago, 2014.

Corrales, Javier, "The Backlash against Market Reforms in Latin America in the 2000s", en Jorge I. Domínguez y Michael Shifter (comps.), 
Constructing Democratic Governance in Latin America, $3^{\mathrm{a}}$ ed., Baltimore, The Johns Hopkins University Press, 2008, pp. 39-70.

Domínguez, Jorge I., "Regional Economic Institutions in Latin America:

Politics, Profits, and Peace", en Miles Kahler y Andrew MacIntyre (comps.), Integrating Regions, Stanford, Stanford University Press, 2013, pp. 107-141.

Fondo Monetario Internacional, Direction of Trade Statistics, distintos años. Fukuyama, Francis, The End of History and the Last Man, Nueva York, The Free Press, 1991.

Grabendorff, Wolf, La seguridad regional en las Américas, Bogotá, Fondo Editorial CREC, 2003.

Haugaard, Lisa, Adam Isacson y Jennifer Johnson, A Cautionary Tale: Plan Colombia's Lessons for U.S. Policy Toward Mexico and Beyond, Washington, Latin America Working Group Education Fund, Center for International Policy y Washington Office for Latin America, 2011.

Hirst, Mónica, "Seguridad en América del Sur: La dimensión regional de sus desafíos políticos”, en Ricardo Lagos (comp.), América Latina: ¿Integración o fragmentación?, Buenos Aires, Edhasa, 2008.

Isacson, Adam, Joy Olson y Lisa Haugaard, Below the Radar: U.S. Military Programs with Latin America, 1997-2007, Washington, Latin America Working Group Education Fund, Center for International Policy y Washington Office for Latin America, 2007.

Krauthammer, Charles, "The Unipolar Moment Revisited”, The National Interest, 70, invierno de 2002-2003, pp. 5-17.

"La larga distancia no borra la íntima amistad", Granma 14 de julio de 2014, http:/ /www.granma/cu/mundo/2014-07-14, último acceso: 15 de julio de 2014.

Leal Buitrago, Francisco, "Una Mirada a la seguridad en la región andina”, en Ricardo Lagos (comp.), América Latina: ¿integración o fragmentación?, Buenos Aires, Edhasa, 2008, pp. 459-489.

Legler, Thomas, "Demise of the Inter-American Democracy Promotion Regime?”, en G. Mace, A. Cooper y T. Shaw, Inter-American Cooperation at a Crossroads, Nueva York, Palgrave MacMillan, 2011, pp. 111-130. , "Beyond Reach? The Organization of American States and Effective Multilateralism”, en Jorge I. Domínguez y Ana Covarrubias, The Handbook of Latin America in the World, Nueva York, Routledge, 2015. 
Maurer, Noel y Gustavo Herrero, "YPF - The Argentine Oil Nationalization of 2012”, Harvard Business School Case, 26 de junio de 2013.

Nicolson, Harold, The Congress of Vienna: A Study in Allied Unity, 1812-1822, Nueva York, The Viking Press, 1961.

O’Donnell, Guillermo y Philippe Schmitter, Transitions from Authoritarian Rule, Baltimore, The Johns Hopkins University Press, 1986.

Ojeda, Mario, Alcances y límites de la política exterior de México, México, El Colegio de México, 1976.

Organización de Estados Americanos, Actas y documentos, Washington, OEA/Ser.P/XVI-E, 14 de diciembre de 1992.

Pérez Llana, Carlos, "Modelos políticos internos y alianzas externas", en Ricardo Lagos (comp.), América Latina: ¿Integración o fragmentación?, Buenos Aires, Edhasa, 2008, pp. 51-87.

Phillips, Nicola, "U.S. Power and the Politics of Economic Governance in the Americas", Latin American Politics and Society, vol. 47, núm. 4, invierno de 2005, pp. 1-25.

Rojas Aravena, Francisco (comp.), La seguridad en América Latina pos 11 de Septiembre, Caracas, Nueva Sociedad, 2003.

Russell, Roberto y Juan Gabriel Tokatlian, "Grand Strategy", en Jorge I. Domínguez y Ana Covarrubias (comps.), Handbook of Latin America in the World, Nueva York, Routledge, 2014.

Saltalamacchia Ziccardi, Natalia, "Regional Multilateralism in Latin America: unASur, AlbA, and CELAC", en Jorge I. Domínguez y Ana Covarrubias, The Handbook of Latin America in the World, Nueva York, Routledge, 2015.

The Huffington Post, 24 de marzo de 2011, http://www.huffingtonpost. com/2011/03/24, último acceso: 13 de julio de 2014.

Tomassini, La política internacional en un mundo posmoderno, Buenos Aires, Grupo Editor Latinoamericano, 1991.

United Nations Peacekeeping Missions, "MINUSTAH", http://www. un.org/en/peacekeeping/missions/minustah/facts.shtml

U.S., Department of State, Bureau of Western Hemisphere Affairs, U.S. Relations with Mexico: Fact Sheet, 2013, http:/ /www.state.gov/r/pa/ei/ bgn/35749.htm, ultimo acceso: 18 de julio de 2014.

Vega Cánovas, Gustavo (comp.), Alcances y límites de la política exterior de México ante el nuevo escenario internacional: Ensayos en honor de Mario Ojeda, México, El Colegio de México, 2009. 
Waltz, Kenneth, "The Emerging Structure of International Politics", en Armand Clesse, Richard Cooper y Yoshikazu Sakamoto (comps.), The International: System after the Collapse of the East-West Order, Dordrecht, Martinus Nijhoff, 1994.

Whitehead, Laurence, "The Fading Regional Consensus in Democratic Governance", en Jorge I. Domínguez y Michael Shifter (comps.), Constructing Democratic Governance in Latin America, $3^{\mathrm{a}}$ ed., Baltimore, The Johns Hopkins University Press, 2008, pp. 13-38.

Xianglin, Mao, Sobre el socialismo en Cuba, Beijing, China Intercontinental Press, 2013. 